\title{
Sistematização do esporte como conteúdo de ensino da Educação Física: um estudo em Cachoeiro de Itapemirim/Espírito Santo
}

Sport Systematization as teaching contente of Physical Education: a study in Cachoeiro do Itapemirim/Espírito Santo

\author{
Mauricio Lopes Spinola \\ Juliana Martins Cassani
}

\begin{abstract}
Resumo: A pesquisa tem como objetivo compreender como os professores do Município de Cachoeiro de Itapemirim/Espírito Santo atuam no processo de seleção e sistematização dos conteúdos esportes, ao longo dos anos da escolarização. Para realização da investigação, utilizamos como referência um questionário elaborado em uma pesquisa nacional intitulada "O trabalho docente na educação básica no Brasil" Oliveira e Vieira (2013) e parte do corpus documental da dissertação de Matos (2013), que por sua vez ofereceu bases para o delineamento metodológico deste artigo. $O$ questionário adaptado possui perguntas introdutórias, fechadas e semiabertas. Os dados evidenciam que os professores ensinam com maior frequência o handebol, basquetebol, futsal e o voleibol. Inferimos sobre a relevância de uma disposição pedagógica que não apenas diversifique, mas, traga complexidade aos conteúdos por meio da experimentação corporal e que, a partir dela, a compreensão dos alunos sobre diferentes elementos que compõem um conteúdo seja ampliada.
\end{abstract}

Palavras-chave: Educação Física. Sistematização de conteúdos de ensino. Licenciados em Educação Física.

\begin{abstract}
The research aims to understand how teachers from the Municipality of Cachoeiro de Itapemirim/Espírito Santo act in the process of sport contents selection and systematization, over the years of schooling. To carry out the investigation, we used as a reference a questionnaire elaborated in a national survey entitled "The teaching work in basic education in Brazil" Oliveira e Vieira (2013) and part of the documentary corpus of Matos' dissertation (2013), which in turn offered bases for the methodological design of this article. The adapted questionnaire has introductory, closed and semi-open questions. The data show that teachers teach handball, basketball, futsal and volleyball more frequently. We infer about the relevance of a pedagogical disposition that not only diversifies, but also brings complexity to the contents through corporal experimentation and, from it, the students' understanding of different elements that make up a content be expanded.
\end{abstract}

Keywords: Physical Education. Systematization of teaching content. Graduates in Physical Education.

\section{Introdução}

A produção científica sobre conteúdos de ensino da Educação Física escolar tem discutido a relevância de pesquisas que abordam o que tem sido ensinado nas aulas, debatendo sobre os tensionamentos colocados pelos 
professores em trabalhar com diferentes práticas, assim como analisando os conteúdos propostos pelos docentes em determinadas séries e anos da escolarização.

Dentre esses artigos, Costa e Nascimento (2006), em pesquisa em que entrevistaram 63 professores do $6^{\circ}$ ao $9^{\circ}$ ano do ensino fundamental, da cidade de Maringá/PR, afirmam que a relevância numérica do esporte como conteúdo pode estar relacionada com a "tradição" colocada pelos docentes em ensinar uma única modalidade esportiva a cada bimestre. Os autores sugerem uma maior articulação da prática pedagógica com a cultura, a fim de que haja uma reconfiguração dos conteúdos ensinados.

Já os resultados obtidos por Pereira e Silva (2004) enfatizam que, dos conteúdos elencados por 22 docentes do ensino médio que atuam no Rio Grande do Sul, $76 \%$ referem-se ao esporte, destacando-se o futsal (44\%) e o voleibol $(28 \%)$. Ao mesmo tempo em que a pesquisa estabelece uma crítica a respeito da centralidade desse conteúdo, sua repetição e pouco aprofundamento, também pondera sobre a importância de a Educação Física contribuir com o desenvolvimento de hábitos de vida saudáveis, proporcionando aos alunos, por meio da prática esportiva, momentos de atividade física regular na escola. Os autores avançam no debate sobre conteúdos de ensino ao sinalizarem a relevância de critérios que levem em consideração as características físicas, psicológicas e sociais dos alunos do ensino médio, no processo de seleção dos conteúdos. Esse movimento traria níveis de complexidade maiores do que aqueles trabalhados no ensino fundamental.

Ambos, Costa e Nascimento (2006) e Pereira e Silva (2004), ressaltam a expressividade numérica com que os conteúdos jogos, dança e ginástica se apresentam. No entanto, de acordo com as pesquisas, o esporte permanece como o conteúdo de maior impacto quantitativo nos discursos dos docentes. Sob o ponto de vista dos pesquisadores, esse panorama tem mostrado 0 distanciamento dos professores em relação aos Parâmetros Curriculares Nacionais e a necessidade de uma diversificação que contemple as orientações do documento. 
As limitações em inserir diferentes conteúdos na prática docente são abordadas nas pesquisas de Silva, Dagostin e Nunez (2009) e Rosário e Darido (2005), em que indicam a insegurança dos professores em ministrar conteúdos que não dominam e a resistência dos alunos em vivenciar práticas que não sejam as esportivas, como possíveis razões pelas quais não há a diversificação do que se ensina.

Silva, Dagostin e Nunez (2009), em estudo com seis docentes do $1^{\circ}$ ao $5^{\circ}$ ano do ensino fundamental de Campo Grande/MS, afirmam ainda que a pouca inserção da dança, por exemplo, é decorrente das representações dos meninos em torno dessa manifestação cultural como prática essencialmente feminina. Uma das questões colocadas por esses autores que, também, reduz as possibilidades de um trabalho diversificado refere-se à organização bimestral dos conteúdos, sendo recorrente o ensino de apenas uma modalidade esportiva a cada dois meses, sobretudo, o voleibol, o futebol, o handebol e o basquetebol.

Os dados da pesquisa de Rosário e Darido (2005) também encontraram uma organização dos conteúdos pautada em bimestres, com um sequenciamento semelhante em todos os anos, o que acompanharia a lógica de outros componentes curriculares. Acrescido a esse cenário, os autores afirmam que a sistematização dos conteúdos na escolarização, pautada nas experiências dos seis docentes do $6^{\circ}$ ao $9^{\circ}$ ano do ensino fundamental, de Rio Claro/SP e Santa Gertrudes/SP, também tem acenado para a importância do estabelecimento de critérios que permitam a diversificação e a complexidade daquilo que se ensina.

Tanto Silva, Dagostin e Nunez (2009), como Rosário e Darido (2005) evidenciam que, embora a produção científica da Educação Física tenha avançado nas discussões acerca da necessidade em diversificar os conteúdos, sinalizando 42 possibilidades de ensino para os professores, essas propostas pouco se concretizam na prática pedagógica. Em nossa análise, esse cenário pode ser gerado pelo distanciamento das pesquisas das práticas produzidas pelos docentes, o que nos faz assumir como referência aquilo que os professores conseguem, têm e são (CHARLOT, 2000). Ao darmos visibilidade 
às suas proposições para o que e quando ensinar, ampliamos as questões aqui colocadas sobre a importância de inserirmos diferentes conteúdos nas aulas de Educação Física.

Pelo exposto, os artigos que assumem como objeto os conteúdos de ensino da Educação Física têm analisado as sugestões dos professores sobre o que ensinar em determinada etapa da escolarização, no entanto, não observamos, tanto em pesquisas de natureza quantitativa (COSTA; NASCIMENTO, 2006; PEREIRA; SILVA, 2004), como qualitativa (SILVA; DAGOSTIN, NUNEZ, 2009; ROSÁRIO; DARIDO, 2005), um panorama quantitativo dos conteúdos a cada ano/série e, por focalizarem sua discussão nos conteúdo em uma etapa específica da escolaridade, os seus dados não nos permitem estabelecer o diálogo com o que se ensina nas etapas anteriores ou subsequentes.

Diante desse cenário, levantamos como problematização para esta pesquisa: como os professores do Município de Cachoeiro de Itapemirim/ES atuam no processo de seleção e sistematização dos conteúdos esportes? Para responder a essa questão, assumimos como objetivo geral compreender como os professores do Município de Cachoeiro de Itapemirim/ES atuam nos processos de seleção dos conteúdos. Interessamo-nos ainda a analisar como os docentes sinalizam os esportes como conteúdo a serem trabalhados, ao longo dos anos da escolarização.

\section{Metodologia}

Esta pesquisa se caracteriza por ser de natureza quali-quantitativa e como colaboradores, professores que atuam nas Redes Municipais e Estaduais de ensino do Município de Cachoeiro de Itapemirim/Espírito Santo.

Em relação aos procedimentos para realizar as entrevistas com os professores, trilhamos os seguintes caminhos metodológicos: em um primeiro momento, fomos até à Formação Continuada do Município de Cachoeiro de Itapemirim/ES, na qual estava sendo realizada nas escolas da região através do portal de cursos da SEDU, tendo como tema BNCC - Base Nacional Comum Curricular. Realizamos o convite aos professores da rede municipal e 
apenas um professor da Educação Infantil (4 a 5 anos) e Ensino Fundamental $\left(6^{\circ}\right.$ a $9^{\circ}$ ano) aceitaram participar da pesquisa.

Posteriormente à formação continuada, apresentamo-nos a diferentes escolas como pesquisadores da FVC - Faculdade Vale do Cricaré, com carta de apresentação do Mestrado. Em seguida, ao convite feito aos diretores das instituições, recebemos a resposta de que cada escola visitada possui de 2 a 3 professores de Educação Física. Assim, tivemos a devolutiva daqueles que tiveram o interesse em participar, totalizando 10 professores.

Para a produção dos dados, tomamos como referência um questionário elaborado em uma pesquisa nacional intitulada "O trabalho docente na educação básica no Brasil”1 Oliveira e Vieira (2013). Os dados da pesquisa realizada no âmbito da Universidade Federal do Espírito Santo, especificamente aqueles relacionados com os conteúdos de ensino da Educação Física, constituíram parte do corpus documental analisado na dissertação de Matos (2013). Por sua vez, os achados de sua pesquisa ofereceram as bases para o delineamento metodológico deste artigo. 0 questionário adaptado possui uma parte introdutória sobre a localidade em que o educador atua, três questões fechadas e nove semiabertas. Da questão introdutória temos as informações da cidade em que os docentes trabalham. Das fechadas, uma se refere ao sexo, outra à formação que possuem e a última sobre a etapa da educação que os docentes trabalham. Das semiabertas, uma está relacionada ao ano de nascimento dos professores, uma com a área do curso superior, uma sobre o tipo de instituição que formou, uma com a área da pós-graduação, uma com a seleção dos conteúdos de ensino, uma com a relação entre os conteúdos de ensino a e série em que se é ensinado o esporte, uma sobre os procedimentos de ensino, outra sobre os procedimentos metodológicos de ensino e a última sobre o grau de importância da educação física para os alunos.

\footnotetext{
${ }^{1}$ Pesquisa coordenada pelo Grupo de Estudos sobre Política Educacional e Trabalho Docente (Gestrado), da Universidade Federal de Minas Gerais. Ver mais em: http://www.gestrado.org/.
} 
Para melhor identificação no capítulo de análise de dados, caracterizamos os professores que se colocaram à disposição para participar da pesquisa, conforme a tabela abaixo:

Quadro 1 - Caracterização dos sujeitos da pesquisa

\begin{tabular}{|c|c|c|c|}
\hline Professor & Curso Superior & Formação & $\begin{array}{l}\text { Rede de Ensino que } \\
\text { atua }\end{array}$ \\
\hline Professor 1 & $\begin{array}{lr}\text { Licenciatura } & \text { em } \\
\text { Educação } & \text { Física - } \\
\text { Instituição } & \text { Pública } \\
\text { Federal. } & \end{array}$ & $\begin{array}{l}\text { Pós-graduação Lato-sensu } \\
\text { em Educação Física } \\
\text { Escolar. }\end{array}$ & Estadual $\left(6^{\circ}\right.$ a $9^{\circ}$ ano $)$ \\
\hline Professor 2 & $\begin{array}{lr}\text { Licenciatura } & \text { em } \\
\text { Educação } & \text { Física - } \\
\text { Instituição } & \text { Pública } \\
\text { Federal. } & \end{array}$ & $\begin{array}{l}\text { Pós-graduação Lato-sensu } \\
\text { em Educação Física } \\
\text { Escolar/Psicomotricidade e } \\
\text { Pós-graduação stricto } \\
\text { sensu em Ciência da } \\
\text { Motricidade Humana. }\end{array}$ & $\begin{array}{l}\text { Estadual }\left(6^{\circ} \text { a } 9^{\circ} \text { ano e }\right. \\
\text { Ensino Médio) }\end{array}$ \\
\hline Professor 3 & $\begin{array}{l}\text { Licenciatura em } \\
\text { Educação Física - } \\
\text { Instituição Particular. }\end{array}$ & $\begin{array}{l}\text { Pós-graduação Lato-sensu } \\
\text { em Psicomotricidade. }\end{array}$ & $\begin{array}{l}\text { Municipal (Educação } \\
\text { Infantil } 4 \text { a } 5 \text { anos e } 6^{\circ} \text { a } \\
9^{\circ} \text { ano) }\end{array}$ \\
\hline Professor 4 & $\begin{array}{l}\text { Licenciatura Plena } \\
\text { em Educação Física } \\
-\quad \begin{array}{l}\text { Instituição } \\
\text { Particular. }\end{array} \\
\end{array}$ & $\begin{array}{l}\text { Pós-graduação Lato-sensu } \\
\text { em Educação Infantil ao } \\
\text { Fundamental. }\end{array}$ & $\begin{array}{l}\text { Municipal (Educação } \\
\text { Infantil } 4 \text { a } 5 \text { anos) }\end{array}$ \\
\hline Professora 5 & $\begin{array}{l}\text { Licenciatura Plena } \\
\text { em Educação Física } \\
\text { - Instituição Pública } \\
\text { Federal. }\end{array}$ & $\begin{array}{l}\text { Pós-graduação Lato-sensu } \\
\text { em } \quad \text { Planejamento } \\
\text { Educacional. }\end{array}$ & Estadual $\left(1^{\circ}\right.$ a $5^{\circ}$ ano $)$ \\
\hline Professora 6 & $\begin{array}{lr}\text { Licenciatura } & \text { em } \\
\text { Educação } & \text { Física, } \\
\text { Fisioterapia } & \mathrm{e} \\
\text { Pedagogia } & - \\
\text { Instituição Particular. }\end{array}$ & $\begin{array}{l}\text { Pós-graduação Lato-sensu } \\
\text { em Educação Física } \\
\text { Escolar e Educação em } \\
\text { Direitos Humanos. }\end{array}$ & Estadual $\left(6^{\circ}\right.$ a $9^{\circ}$ ano $)$ \\
\hline Professora 7 & $\begin{array}{l}\text { Licenciatura } r \text { em } \\
\text { Educação Física e } \\
\text { Técnica } \quad \text { em } \\
\text { Enfermagem } \\
\text { Instituição Particular. }\end{array}$ & $\begin{array}{l}\text { Pós-graduação Lato-sensu } \\
\text { em Educação Física } \\
\text { Escolar. }\end{array}$ & Estadual (Ensino Médio) \\
\hline Professora 8 & $\begin{array}{lr}\text { Licenciatura } & \text { em } \\
\text { Educação } & \text { Física, } \\
\text { Técnica } & \text { em } \\
\text { Enfermagem } & \text { e } \\
\text { Pedagogia } & - \\
\text { Instituição Particular } \\
\end{array}$ & $\begin{array}{l}\text { Pós-graduação Lato-sensu } \\
\text { em Educação Especial e } \\
\text { Inclusiva. }\end{array}$ & Estadual (Ensino Médio) \\
\hline Professor 9 & $\begin{array}{l}\text { Licenciatura em } \\
\text { Educação Física - } \\
\text { Instituição Particular. }\end{array}$ & $\begin{array}{l}\text { Pós-graduação Lato-sensu } \\
\text { em Educação Física } \\
\text { Escolar. } \\
\end{array}$ & $\begin{array}{l}\text { Municipal (Educação } \\
\text { Infantil } 4 \text { a } 5 \text { anos e } 1^{\circ} \text { a } \\
5^{\circ} \text { ano) }\end{array}$ \\
\hline Professor 10 & $\begin{array}{l}\text { Licenciatura em } \\
\text { Educação Física - } \\
\text { Instituição Particular. }\end{array}$ & $\begin{array}{l}\text { Pós-graduação Lato-sensu } \\
\text { em Educação Física } \\
\text { Escolar. } \\
\end{array}$ & Municipal $\left(6^{\circ}\right.$ a $\left.9^{\circ}\right)$ \\
\hline
\end{tabular}

Fonte: Os autores. 


\section{Os conteúdos selecionados pelos professores}

Com a finalidade de ressaltar os conteúdos de ensino ministrados pelos educadores, organizamos as respostas dos professores com relação ao questionário. Além das opções colocadas no questionário (esporte, dança, jogo, brincadeira, lutas, ginástica e outros), o educador podia estabelecer uma relação entre conteúdos de ensino e a série ou ano em que se ensina especificamente o esporte, o que será visto em posteriores análises.

Em uma análise inicial das respostas dos docentes, estavam vigentes: as brincadeiras (21), os jogos (11), os esportes (7), a dança (6), a ginástica (6), as lutas (2), e outros conteúdos (3). Em estudo semelhante, Marzinek (2004) identificou que os conteúdos mais trabalhados nas aulas de Educação Física são os esportes. Desses, o autor identificou aqueles que são privilegiados, como: futebol, voleibol, basquetebol e handebol, sendo eles, geralmente, os mais populares entre os alunos de Ensino Fundamental e Médio. Contudo, os nossos dados apresentam uma nova formatação em relação ao que alguns pesquisadores apresentam, uma vez que, as brincadeiras e os jogos se apresentam com destaque quantitativo em relação aos esportes.

Com o intuito de darmos visibilidade aos conteúdos de ensino indicados pelos professores, bem como à diversidade de práticas anunciadas pelos educadores, organizaremos as suas respostas em gráficos, de acordo com a ordem decrescente dos dados. No caso, o Gráfico 1 apresenta as brincadeiras registradas pelos professores:

Gráfico 1 - Possibilidades de ensino para o conteúdo brincadeiras

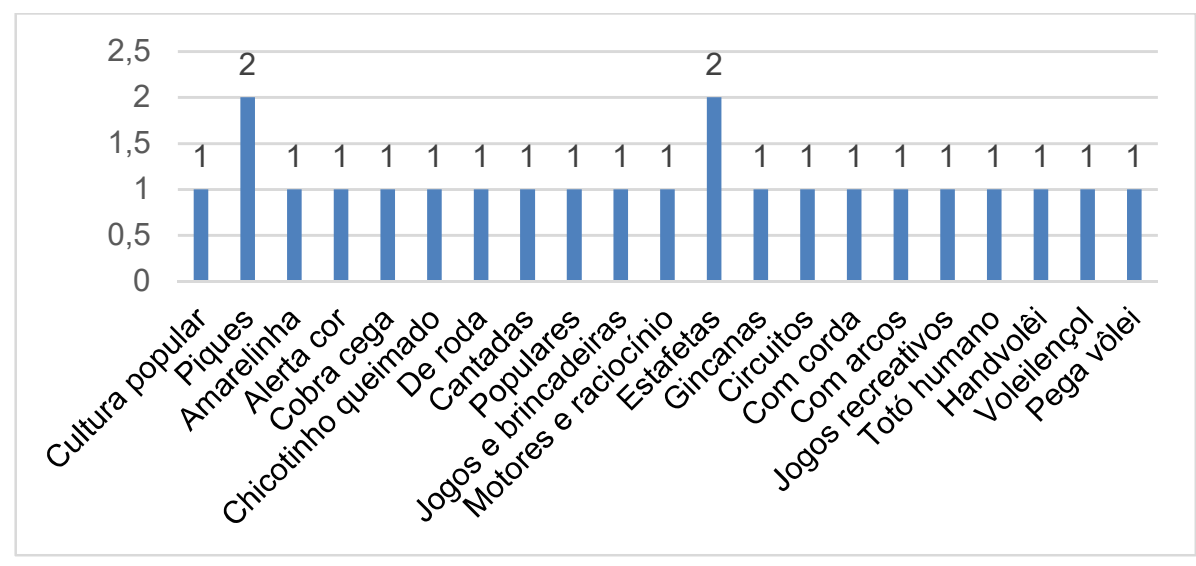

Fonte: Os autores. 
O Gráfico 1 evidencia a diversidade numérica das brincadeiras sugerindo-nos que sua referência são os conteúdos estruturantes, a partir deles, inserir em diferentes possibilidades de ensino que possuam características semelhantes.

Esse é o caso da denominação brincadeiras populares, que trata de conteúdos de modo mais amplo e que poderia agrupar a cultura popular (1), os piques (1), a amarelinha (1), o alerta cor (1), a cobra cega (1), o chicotinho queimado (1), as brincadeiras de roda (1), brincadeiras cantadas (1) e com corda (1). Esses achados nos remetem ao estudo de Borba (2007), ao afirmar sobre a necessidade de as crianças explorarem, em seus processos de aprendizagem, o brincar. Para o autor, as crianças se constituem, ao brincar, como sujeitos de experiência social, organizando com autonomia suas ações e interações, elaborando planos e formas de ações conjuntas, criando regras de convivência social e de participação nas brincadeiras. Assim, com base nas respostas dos professores, temos compreendido que a brincadeira permite às crianças não apenas reproduzirem uma cultura adulta, mas, sim, inventarem outras formas de aprendizado.

Com o objetivo de problematizar as práticas elencadas em brincadeiras, optamos por articular os dados referentes a esse conteúdo com aqueles obtidos em jogos, conforme Gráfico 2:

Gráfico 2 - Possibilidades de ensino para o conteúdo jogos

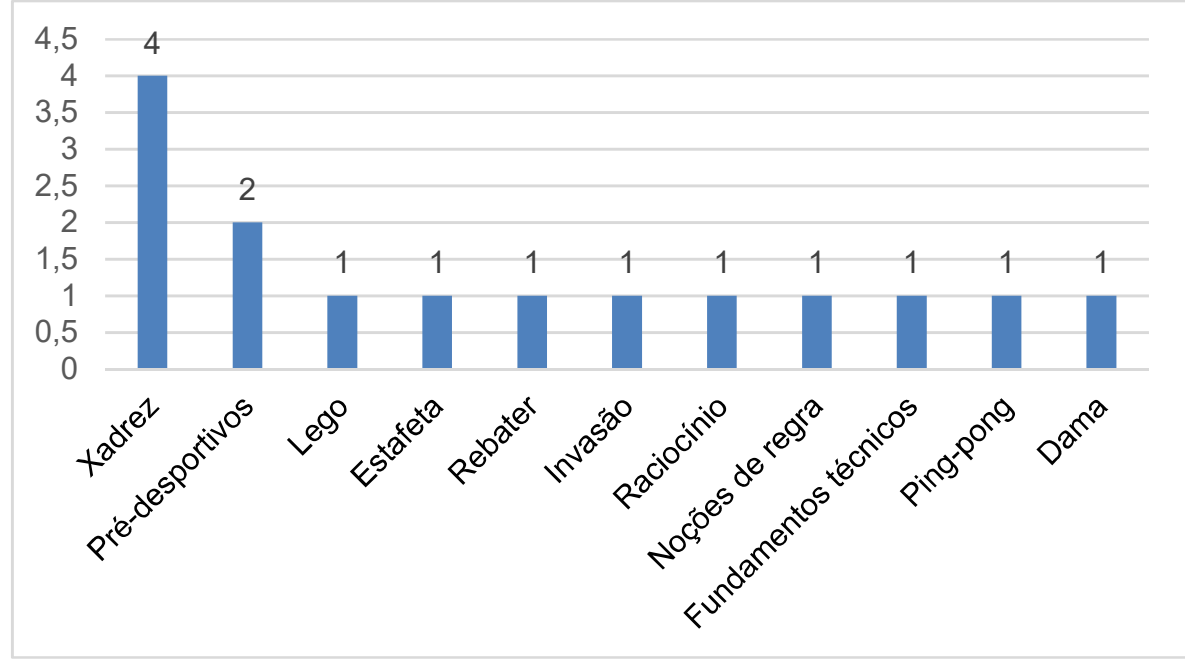

Fonte: Os autores. 
Nos questionários respondidos pelos professores, identificamos, assim como ocorre com as brincadeiras, a presença dos estafetas (1). Do mesmo modo, percebemos que os jogos de tabuleiro têm sido privilegiados em suas aulas, presentes da seguinte maneira: xadrez (4), lego (1), ping pong (1) e dama (1), o que corresponde a $47 \%$ dos jogos indicados.

Associados a jogos pré-desportivos, ou seja, práticas que visam iniciar o ensino dos esportes por meio de jogos encontram-se os jogos de rebater (1), os jogos de invasão (1) e os fundamentos técnicos. Parece-nos, em um primeiro momento, que esses dados se confundem com aqueles presentes nas brincadeiras, acenando para certa confusão conceitual entre os docentes, no que se refere àquilo que se ensina. Isto é, no Gráfico 1 , vimos que os professores sinalizam jogos pré-desportivos como brincadeiras e, no Gráfico 2 , encontramos jogos que se assemelham às categorizações propostas pela Base Nacional Comum Curricular (BRASIL, 2019), no que se refere aos esportes.

Em leitura deste documento, identificamos que os esportes têm sido classificados com base em critérios de cooperação, interação com 0 adversário, desempenho motor e objetivos táticos da ação. A partir desses princípios, os esportes são prescritos para serem ensinados da seguinte maneira: esportes de marca, de precisão, técnico-combinatório, rede/quadra dividida ou parede de rebote, campo e taco, invasão ou territorial e de combate (BRASIL, 2019). Esses dados nos permitem inferir que os professores, ao sinalizarem as práticas que são desdobramentos dos conteúdos estruturantes, acabam por aproximar conceitualmente brincadeiras, jogos e esportes, o que pode gerar repetição de conteúdo, bem como ausência de complexidade em relação àquilo que se ensina. Ou seja, na medida em que a seleção dos conteúdos não está definida de modo preciso, é possível que eles também se repitam ao longo da escolarização, porém, com terminologias diferentes.

Para analisarmos como o conteúdo esporte tem sido indicado como conteúdo a ser trabalhado nas aulas de Educação Física, elaboramos o Gráfico 3, abaixo: 
Gráfico 3 - Possibilidade de ensino para o conteúdo esporte

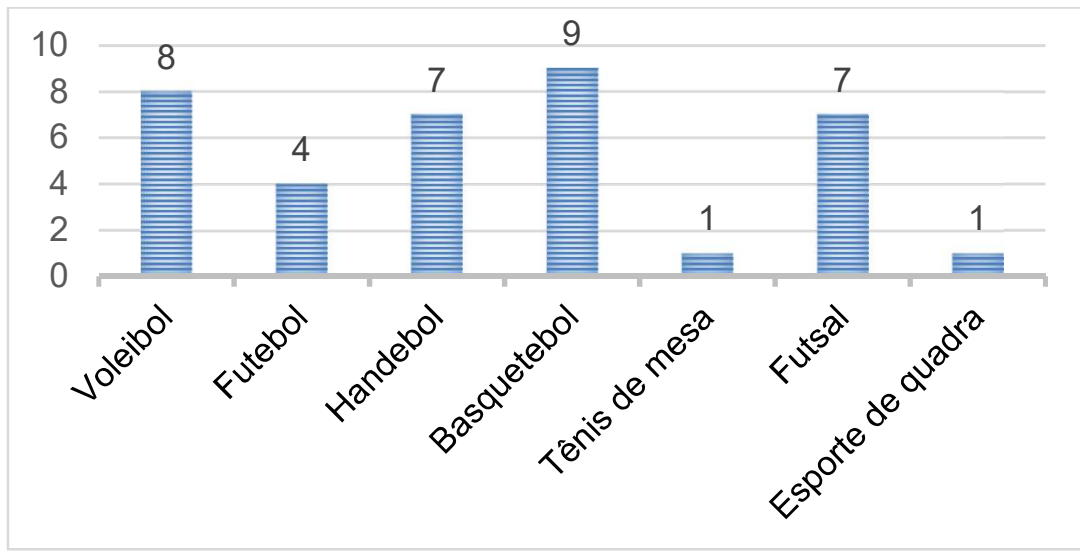

Fonte: Os autores.

Os resultados obtidos por esta pesquisa se aproximam dos dados de Darido (2001), sobre as modalidades esportivas que são privilegiadas pelos professores, como basquete, vôlei e futebol. No caso das entrevistas com os professores, aparecem com maior relevância numérica o basquete (9), o voleibol (8), o handebol (7) e o futsal (7).

Quando comparamos esses números com os gráficos anteriores, notamos que, embora os conteúdos brincadeiras e jogos tenham maior diversificação, é no conteúdo esporte que há maior concentração quantitativa no que se refere às práticas sinalizadas pelos professores. Diante do elevado número de professores que indica ensinar os esportes, consideramos, por outro lado, a necessidade de analisar o modo como esses esportes são trabalhados, pois, muitas vezes, ele está mais relacionado com a preocupação dos alunos em ter uma "atividade de lazer" na Educação Física, do que de fato ser sistematizado ao longo dos anos da escolarização. O que se pretende, por vezes, é mais um conjunto de atividades relacionadas ao futebol, mas, sem o devido aprofundamento e intervenção do professor, como afirma Arruda Júnior (2009).

Kravchychyn, Oliveira e Cardoso (2008) também afirmam que a centralidade do esporte nas aulas de Educação Física pode estar relacionada com a opção dos docentes em ministrar conteúdos com os quais possuam maior aproximação e domínio. Os autores sinalizam, também, que a pouca adesão dos alunos quando o esporte não é ensinado, se constitui em outro motivo pelo qual esse conteúdo é privilegiado nas aulas. 
Se, em determinado momento, os artigos científicos sinalizam o desinteresse dos alunos por práticas que não sejam as esportivas, como uma das razões para a baixa diversificação do que se ensina, em outro, encontramos indícios de que essa falta de motivação pelas aulas é gerada pelo pouco aprofundamento das dimensões técnica e tática no trato com o conteúdo. Esses tensionamentos nos levam a perguntar: quais as implicações de centralizarmos o processo de seleção dos conteúdos no interesse dos alunos, quando eles se voltam para algo específico? Como se configurariam as suas preferências, se eles não experimentam outras práticas?

Santos (2013) nos ajuda a compreender essas questões, pois, analisa, por meio de narrativas produzidas com alunos do último ano do ensino médio, a relação que eles estabelecem com a escolarização da Educação Física. Ainda que fosse prazeroso aos alunos escolher o que gostariam de aprender na educação infantil e no ensino fundamental I, a semelhança entre as práticas vivenciadas em diferentes espaços com os conteúdos aprendidos nas aulas foi apresentada pelos adolescentes como um dos motivos pelos quais desconsideram a Educação Física como um lugar de aprendizagem.

A baixa mediação pedagógica sinalizada por Santos (2013) nos oferece fundamentos para inferir que considerar as preferências dos alunos no processo de seleção dos conteúdos pode reconhecer o seu lugar de autoria e autonomia nas aulas, no entanto, também, pode levar à homogeneidade e repetição daquilo que se ensina. Em relação ao ensino do conteúdo dança, organizamos o seguinte gráfico: 
Gráfico 4 - Probabilidade para o conteúdo dança

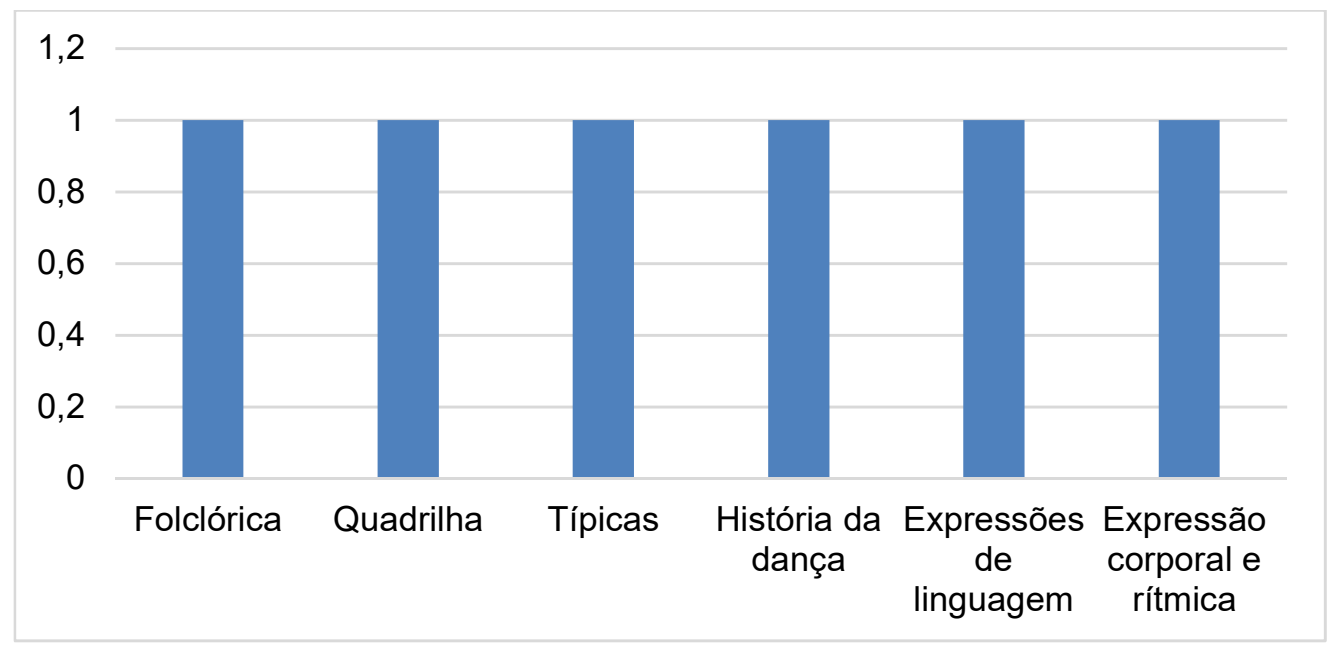

Fonte: Os autores.

O gráfico nos apresenta diversas formas de ensinar a dança como componente curricular. Um dos requisitos da nova BNCC é considerar a Educação Física como um fenômeno da cultura corporal, uma vez que, o movimento corporal manifesta comportamentos que não são expressos com palavras.

Observando o Gráfico 4, percebemos que existe uma variedade na representatividade da dança, onde a mesma é caracterizada por seis tipos diferenciados. Ao privilegiarem danças que nos remetem à cultura popular, como danças folclóricas (1), típicas (1), quadrilhas (1), notamos que as respostas dos professores se aproximam dos achados de Matos (2013). Em sua pesquisa, os professores de diferentes Municípios do Estado do Espírito Santo também privilegiam as danças folclóricas, dentre elas, a dança italiana, ítalo-germânica, com fitas, regionais e quadrilha. Em ambos os casos, podemos afirmar que há um movimento, por parte dos professores, de valorização da cultura local no processo de seleção de conteúdo, por meio da apropriação de manifestações artísticas que expressam a própria constituição histórica do Brasil e do Espírito Santo.

Além disso, a indicação dos professores à dança como expressões de linguagem (1) e expressão corporal e rítmica sugerem a escola como um espaço de exploração de diferentes linguagens, em que circulam os saberes acadêmicos e culturais, reconhecidos pelo seu conjunto de técnicas e estéticas 
que lhes são pertinentes. A fim de analisarmos as especificidades do conteúdo ginástica, demos visibilidade às indicações dos professores, conforme demonstra o Gráfico 5:

Gráfico 5 - Possibilidade de ensino para o conteúdo ginástica

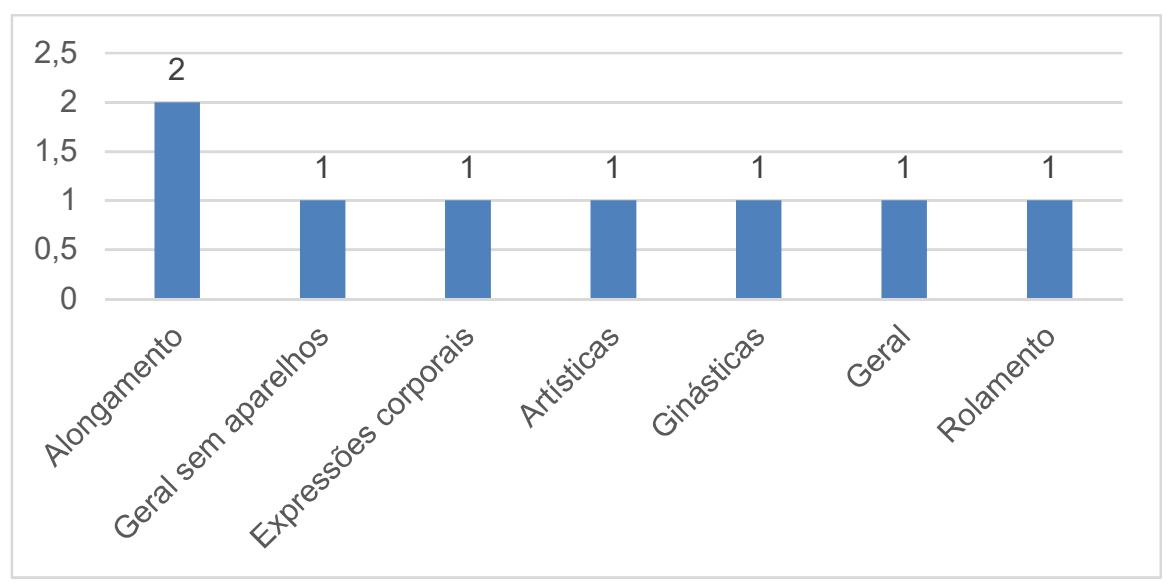

Fonte: Os autores.

Para compreender os dados do Gráfico 5, também dialogamos com Matos et al. (2013), em pesquisa que mapeou os conteúdos de ensino presentes nos artigos veiculados em periódicos (1981-2010). Os autores sinalizam que a produção científica da Educação Física tem especificado o debate sobre esse conteúdo em práticas como a ginástica acrobática (1), artística (1), circense (5), geral (2) e rítmica (2), resultados esses que se aproximam daqueles encontrados nos.

Os dados referentes aos questionários sugerem certo esvaziamento dos professores em relação ao ensino das diferentes modalidades ginásticas como conteúdo da Educação Física, possivelmente, pela própria lacuna apresentada pela BNCC, em que a ginástica deixa de ser compreendida como conteúdo estruturante, para ser considerada como um desdobramento dos esportes. No referido documento, ela é vista como modalidade esportiva técnicocombinatória, pois, reúne ginásticas nas quais o resultado da ação motora se constitui pela qualidade do movimento (ginástica artística, ginástica rítmica, nado sincronizado, patinação artística, saltos ornamentais etc.). Nesse caso, os professores indicam apenas a ginástica artística (1) como conteúdo de ensino, privilegiando outras práticas que não se diferenciam tanto em suas especificidades. 
Por outro lado, os professores acenam, ainda, para certa aproximação entre esse conteúdo com o mercado de trabalho e com práticas mais voltadas para a saúde, dada a presença do alongamento (2). Esse achado, também, se aproxima do que prescreve a BNCC para a unidade temática Ginásticas. No documento, essas práticas compreendem a ginástica geral, ginásticas de condicionamento físico; e ginásticas de conscientização corporal. As ginásticas de condicionamento físico se caracterizam pela exercitação corporal orientada à melhoria do rendimento, da condição física individual ou à modificação da composição corporal. Já as ginásticas de conscientização corporal reúnem práticas que empregam movimentos suaves e lentos, voltados para a obtenção de uma melhor percepção sobre o próprio corpo.

O gráfico 6 apresenta os dados referentes a outros conteúdos indicados pelos professores:

Gráfico 6 - Probabilidade para outros conteúdos de ensino

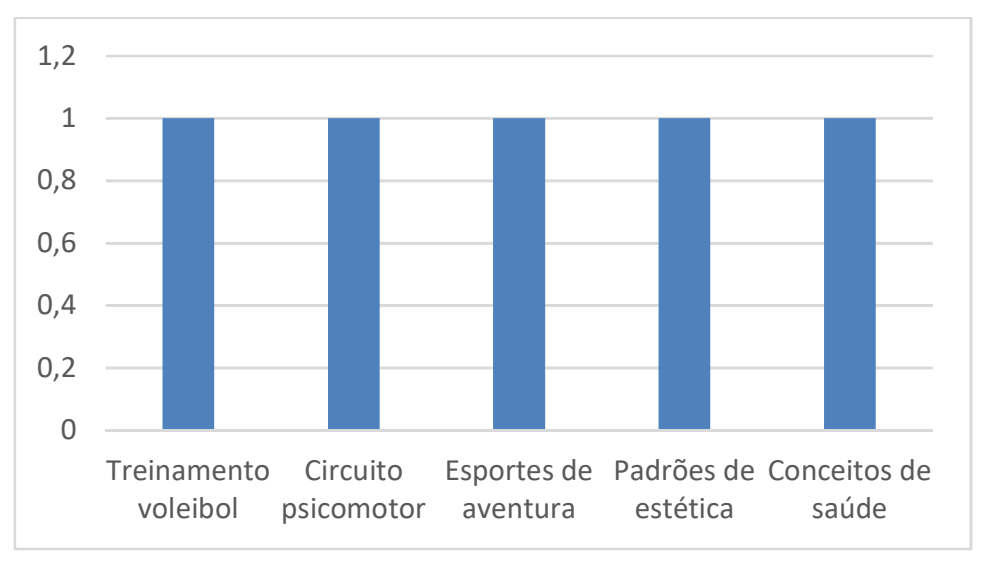

Fonte: Os autores.

O Gráfico 6 evidencia outras possibilidades de ensino que paulatinamente têm sido incorporadas às aulas de Educação Física, como os esportes de aventura, bem como o debate sobre saúde e estética. Nota-se também que há, entre os professores, a ideia de que a Educação Física escolar se constitui como espaço para treinamento esportivo.

\section{A sistematização do esporte ao longo da escolarização}

Com o objetivo de estabelecermos uma relação entre conteúdos de ensino e a série/ano em que os educadores ensinam especificamente o 
esporte, segue os dados de acordo com as respostas dos professores, como mostra o quadro 2:

\section{Quadro 2 - Relação de conteúdos de ensino com série/ano}

\begin{tabular}{|c|c|c|}
\hline Série/Ano & Conteúdos & Procedimentos metodológicos \\
\hline \multirow{3}{*}{$\begin{array}{l}\text { Educação } \\
\text { Infantil }\end{array}$} & $\begin{array}{l}\text { Cantigas de roda, atividades } \\
\text { psicomotoras, lateralidade e } \\
\text { equilíbrio, expressão corporal, } \\
\text { morto vivo, coelhinho sai da } \\
\text { toca e circuitos diversificados } \\
\text { com variações. }\end{array}$ & $\begin{array}{l}\text { Conversa informal sobre a importância da } \\
\text { educação física, a importância do "brincar" } \\
\text { nessa fase principalmente de } \\
\text { desenvolvimento da criança que é de suma } \\
\text { importância. }\end{array}$ \\
\hline & $\begin{array}{l}\begin{array}{l}\text { Introdução do conteúdo de } \\
\text { basquete }\end{array} \\
\end{array}$ & Teoria escrita, prática e avaliação. \\
\hline & $\begin{array}{lr}\text { Atividades } & \text { psicomotoras, } \\
\text { brincadeiras } & \text { lúdicas, } \\
\text { conhecimento sobre o próprio } \\
\text { corpo e vivência do esporte. }\end{array}$ & $\begin{array}{l}\text { Vivenciando a prática de forma lúdica } \\
\text { visando a experiência neste momento e } \\
\text { não ao esporte propriamente dito. }\end{array}$ \\
\hline $\begin{array}{l}5^{\circ} \text { Ano do } \\
\text { Ensino } \\
\text { Fundamental }\end{array}$ & 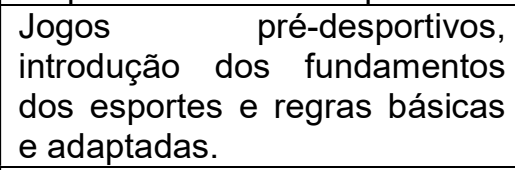 & $\begin{array}{l}\text { Aulas teóricas/práticas e recursos áudio } \\
\text { visuais. }\end{array}$ \\
\hline \multirow{3}{*}{$\begin{array}{l}6^{\circ} \text { Ano do } \\
\text { Ensino } \\
\text { Fundamental }\end{array}$} & 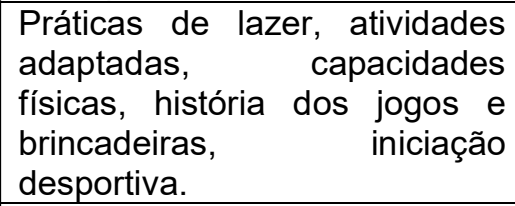 & Aulas práticas, teóricas e TIC (tecnologias). \\
\hline & $\begin{array}{l}\text { Alongamento, aquecimento, } \\
\text { atletismo, avaliação física e } \\
\text { brincadeiras. }\end{array}$ & Aulas teóricas conciliadas com a prática. \\
\hline & $\begin{array}{l}\text { Ensino de regras de } \\
\text { modalidades (vôlei, handebol, } \\
\text { futsal, futebol e basquete). }\end{array}$ & Teoria escrita, prática e avaliação. \\
\hline \multirow{3}{*}{$\begin{array}{l}7^{\circ} \text { Ano do } \\
\text { Ensino } \\
\text { Fundamental }\end{array}$} & $\begin{array}{l}\begin{array}{l}\text { Alongamento, } \\
\text { atletismo e } \\
\text { esportivas }\end{array} \\
\end{array}$ & $\begin{array}{l}\text { Aulas expositivas com recurso de áudio e } \\
\text { vídeo. }\end{array}$ \\
\hline & $\begin{array}{l}\text { Fundamentos, táticas } \\
\text { simplificadas, regras básicas, } \\
\text { coletivos organizados, voleibol, } \\
\text { handebol, futsal, tênis de } \\
\text { mesa, jogos da cultura popular } \\
\text { e brincadeiras. }\end{array}$ & $\begin{array}{l}\text { Aulas expositivas, vídeo, textos, jogos, } \\
\text { debates e brincadeiras. }\end{array}$ \\
\hline & 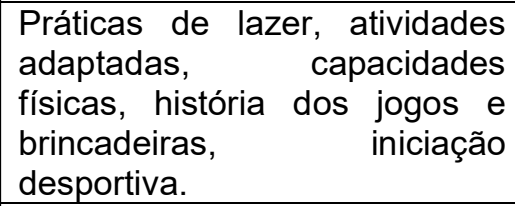 & Aulas práticas, teóricas e TIC (tecnologias). \\
\hline \multirow{2}{*}{$\begin{array}{l}8^{\circ} \text { ano do } \\
\text { Ensino } \\
\text { Fundamental }\end{array}$} & 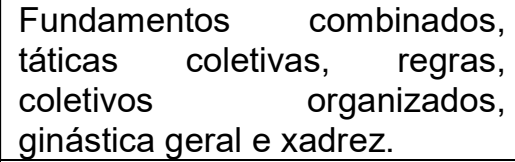 & $\begin{array}{l}\text { Aulas expositivas, jogos, vídeos, jornais, } \\
\text { debates, visitas e brincadeiras. }\end{array}$ \\
\hline & $\begin{array}{lr}\text { Práticas de lazer, atividades } \\
\text { adaptadas, } & \text { capacidades } \\
\text { físicas, história dos jogos e } & \text { jogos } \\
\text { brincadeiras, } & \text { iniciação } \\
\text { desportiva. } & \end{array}$ & Aulas práticas, teóricas e TIC (tecnologias). \\
\hline
\end{tabular}




\begin{tabular}{|c|c|c|}
\hline \multirow{3}{*}{$\begin{array}{l}9^{\circ} \text { Ano do } \\
\text { Ensino } \\
\text { Fundamental }\end{array}$} & $\begin{array}{l}\text { Fundamentos } \\
\text { (aperfeiçoamento técnico), } \\
\text { táticas de jogo, regras, } \\
\text { coletivos com funções táticas, } \\
\text { xadrez competitivo e tênis de } \\
\text { mesa recreativo. }\end{array}$ & $\begin{array}{l}\text { Aulas expositivas, jogos, vídeos, jornais, } \\
\text { debates, intercâmbios, trabalhos } \\
\text { extraclasse. }\end{array}$ \\
\hline & $\begin{array}{l}\text { Cultura corporal do movimento } \\
\text { e jogos pré-desportivos. }\end{array}$ & Aquecimento e pequenos jogos. \\
\hline & $\begin{array}{l}\text { Jogos pré-desportivos } \mathrm{e} \\
\text { noções de regras. }\end{array}$ & Aulas práticas, teóricas e TIC (tecnologias). \\
\hline \multirow{3}{*}{$\begin{array}{l}1^{\circ} \text { Ano } \\
\text { Ensino } \\
\text { Médio }\end{array}$} & \begin{tabular}{lr} 
Iniciação & \multicolumn{2}{c}{ esportiva, } \\
fundamentos & técnicos \\
sistema de jogo. &
\end{tabular} & História e regras dos desportos. \\
\hline & $\begin{array}{l}\text { Apresentação técnica dos } \\
\text { esportes (dança, jogo, } \\
\text { brincadeira, lutas, ginásticas), } \\
\text { tática e regras. }\end{array}$ & $\begin{array}{l}\text { Explicação teórica, prática, repetição dos } \\
\text { movimentos (fundamentos), treinos e } \\
\text { assimilação de conteúdo através de provas } \\
\text { e questionários. }\end{array}$ \\
\hline & $\begin{array}{l}\text { Handebol, Futsal, basquete e } \\
\text { vôlei. }\end{array}$ & Teoria e prática. \\
\hline \multirow{4}{*}{$\begin{array}{l}2^{\circ} \text { Ano } \\
\text { Ensino } \\
\text { Médio }\end{array}$} & $\begin{array}{l}\text { Fundamentos técnicos, } \\
\text { fundamentos táticos e sistema } \\
\text { de jogo. }\end{array}$ & Jogo propriamente dito. \\
\hline & $\begin{array}{l}\text { Atividades com corda com } \\
\text { variações, } \\
\text { recreativo, basquetinho } \\
\text { lateralidade, cquilíbrio e e } \\
\text { cones, estafetas variadas, } \\
\text { telefone sem fio e futebol } \\
\text { dirigido. }\end{array}$ & $\begin{array}{l}\text { Conversa informal sobre a importância da } \\
\text { educação física, a importância do "brincar" } \\
\text { nessa fase de desenvolvimento motor, } \\
\text { afetivo e social, onde a criança começa } \\
\text { adquirir o gosto da prática recreativa. }\end{array}$ \\
\hline & $\begin{array}{l}\text { Apresentação técnica dos } \\
\text { esportes (dança, jogo, } \\
\text { brincadeira, lutas, ginasticas), } \\
\text { tática e regras. }\end{array}$ & $\begin{array}{l}\text { Explicação teórica, prática, repetição dos } \\
\text { movimentos (fundamentos), treinos e } \\
\text { assimilação de conteúdo através de provas } \\
\text { e questionários. }\end{array}$ \\
\hline & $\begin{array}{l}\text { Handebol, Futsal, basquete e } \\
\text { vôlei }\end{array}$ & Teoria e prática. \\
\hline $\begin{array}{l}3^{\circ} \mathrm{Ano} \\
\text { Ensino } \\
\text { Médio }\end{array}$ & Jogo propriamente dito. & Aplicabilidade do jogo e contextualização. \\
\hline
\end{tabular}

Fonte: Os autores

O Quadro 2 demonstra a relação estabelecida entre os conteúdos de ensino, procedimentos metodológicos e os anos da escolarização, sugerindo os critérios utilizados pelos professores na sistematização do conhecimento, tais como: para quem ensinar, o que ensinar e quando ensinar, ou seja, as especificidades cognitivas, motoras e sociais dos alunos, a natureza do próprio conteúdo e o contexto de aprendizagem articulado com um nível de complexidade daquilo que se ensina.

Possivelmente, as brincadeiras e os jogos aparecem com expressividade quantitativa na educação infantil pelas características motoras, cognitivas, sociais e culturais da criança, que encontra no movimento corporal 
a sua principal linguagem e vê nessas práticas um espaço de autonomia, criatividade e espontaneidade. Porém, a inserção do esporte (basquete) nessa etapa de ensino, mesmo que expresse o movimento dos docentes em ajustá-lo com base nas necessidades das crianças, dada a sua estrutura e natureza, pode não representar um conteúdo indicado para a educação infantil, haja vista a presença de regras orientadoras de ações extremamente complexas e que não valorizam a singularidade dos sujeitos de aprendizagem de zero a seis anos.

A presença de terminologias como "atividades psicomotoras, lateralidade, equilíbrio" para a Educação Infantil sugerem que, para os professores, os conteúdos da Educação Física não são os jogos ou as brincadeiras, mas, esses se constituem em instrumentos, em uma metodologia para o desenvolvimento das capacidades físicas. Nesse caso, as intencionalidades pedagógicas dos docentes estariam voltadas para a ampliação do repertório físico-motor das crianças e dos adolescentes, movimento esse reiterado pela inserção dessas temáticas em brincadeiras (Gráfico 1) e jogos (Gráfico 2).

Os dados presentes no Quadro 2 também sinalizam que, dentre o $5^{\circ} \mathrm{e}$ $9^{\circ}$ ano, os professores privilegiam o ensino de jogos que visam a inserir os alunos nos esportes, por meio de jogos pré-desportivos. No caso, observamos esses aspectos em terminologias como: "introdução dos fundamentos dos esportes e regras básicas e adaptadas; iniciação desportiva; fundamentos, táticas simplificadas, regras básicas".

O lugar ocupado pelo esporte do $5^{\circ}$ ao $9^{\circ}$ ano é semelhante ao panorama investigado por Rosário e Darido (2005), no qual, esse conteúdo, também, se configura como aquele de maior expressividade numérica no ensino fundamental II. Os autores afirmam ser a experiência do docente, o contexto da escola e o interesse dos alunos os elementos que têm pautado as escolhas do professor em privilegiar o esporte nessa etapa de ensino. Porém, em nossos dados, também, notamos essa possível relação entre os conteúdos jogos e esportes. 
O mapeamento realizado com os professores de Cachoeiro de Itapemirim/ES indicia que a expressividade numérica do esporte no ensino fundamental II pode ser decorrente do modo como o professor trabalha com o jogo. O seu crescimento gradativo, à medida que os anos da escolarização avançam, pode ser decorrente de uma compreensão na qual o jogo se configura como prática anterior e essencial à aprendizagem dos elementos do esporte, já que, dentre as suas características, há a necessidade de delimitação de um espaço-tempo para a sua realização e o estabelecimento de regras, mesmo (re)inventadas (CAILLOIS, 1990). Dessa maneira, o lugar ocupado pelos jogos no ensino fundamental II sugere uma representatividade muito maior para o esporte do que aquela apresentada quantitativamente, fundamentando os processos de seleção e sistematização dos jogos.

Já em relação aos procedimentos metodológicos indicados pelos professores, percebemos que, na medida em que os anos da escolarização avançam, também, há maior complexidade e diversidade em relação aos meios utilizados para o ensino da Educação Física. Expressões utilizadas como "aulas expositivas, vídeos, jornais, debates, visitas; recursos áudio visuais; TICs (tecnologias)", evidenciam maior diversidade em relação a esses procedimentos e, ao mesmo tempo, o interesse dos professores em trazer para as aulas recursos didáticos que estão presentes cotidianamente nas práticas dos alunos, como o uso de diferentes tecnologias. Também sinalizamos que a presença de vídeos, jornais, debates e visitas podem ser formas utilizadas pelos docentes para que, além de deixarem a aula mais rica culturalmente, também, sejam meios para realização de pesquisa e trabalhos, por parte dos alunos.

No que se refere ao ensino do esporte propriamente dito, notamos que é a partir do $9^{\circ}$ ano que ele é ensinado com maior aprofundamento, considerando a sua lógica interna e diferenças entre as modalidades. Isso pode ser identificado por terminologias como: "fundamentos (aperfeiçoamento técnico), táticas de jogo, coletivos com funções táticas; fundamentos técnicos e sistema de jogo; apresentação técnica dos esportes". 
É interessante ainda notar a presença, no $3^{\circ}$ ano, do conteúdo "jogo propriamente dito" e, como procedimento metodológico, a "aplicabilidade do jogo e contextualização".

Esses dados podem ser interpretados de duas maneiras: a) o ensino e a aprendizagem do esporte tiveram complexidade tal nos anos anteriores, que os professores atuam no sentido de que os alunos o vivenciem por meio de situações reais de jogo; b) recaímos ao contexto apresentado pela produção acadêmica da área, em que, na medida em que os anos avançam, a Educação Física passa a ser compreendida como lazer, ou seja, um espaço em que os alunos apenas "descansam" ou se "veem livres" de outros componentes curriculares, não havendo a mediação do professor nos processos de ensino e de aprendizagem.

Assim, o impacto numérico do esporte, a partir do $6^{\circ}$ ano, é semelhante àqueles apontados no estudo de Santos (2013), o qual evidencia, sob o ponto de vista dos alunos, o lugar privilegiado assumido por esse conteúdo. Esse panorama tem levado aqueles que se encontram nas séries finais do ensino médio ao desinteresse pelas aulas de Educação Física, haja vista a profundidade com que o esporte é abordado e, ainda, por não aprenderem conteúdos diferentes. Essa falta de motivação é gerada logo nas séries finais do ensino fundamental, pois, aquilo que representava algo novo, o esporte, por ocasião de sua entrada no $6^{\circ}$ ano, passa a ser desestimulante por ser ensinado de maneira repetitiva e sem aumento de complexidade.

Quanto aos procedimentos metodológicos indicados pelos docentes, notamos que, além de manterem aqueles presentes do $5^{\circ}$ aos $8^{\circ}$ anos, também, trazem mais elementos que reforçam a ideia de que, a partir do $9^{\circ}$ ano, o ensino dos esportes se faz mais complexo. As terminologias utilizadas pelos professores remetem-nos a isso, como: "história e regras dos desportos; explicação teórica, prática, repetição dos movimentos (fundamentos), treinos e assimilação de conteúdo através de provas e questionários".

Em um primeiro momento, é preciso indagarmos sobre o uso de termos como "repetição dos movimentos (fundamentos) e treinos", como procedimentos metodológicos nas aulas de Educação Física", haja vista que, 
esses não são objetivos pelos quais esse componente curricular deva focalizar - comprometendo, inclusive, o amplo debate no campo acadêmico acerca das finalidades da Educação Física que, em sua dimensão cultural, fundamenta-se em princípios de formação humana inclusiva.

É preciso, também, problematizar o lugar que as provas e os questionários assumem como instrumentos avaliativos, ao final da escolarização. Esses dados nos aproximam da pesquisa de Santos et al. (2016), ao afirmarem que, com o avanço do processo de escolarização, há também necessidade de a Educação Física produzir saberes de maneira articulada com aqueles priorizados pela escola, delimitando uma forma de compreender a linguagem e o seu processo de aprendizado. Por esse motivo, a avaliação aparece como provas e questionários, que são instrumentos comuns a outros componentes curriculares.

Os dados elaborados com base nas entrevistas dos professores permitem-nos estabelecer diálogo com Matos (2013), sobre a necessidade de estabelecermos princípios didáticos em relação ao ensino dos conteúdos, considerando a sua distribuição ao longo dos anos de modo vertical e horizontal.

De acordo com a autora, do ponto de vista didático, trabalhar o conteúdo de modo vertical é pensar no que se ensina ao longo das séries, por meio da continuidade e da sequência. A continuidade estaria relacionada com a necessidade de repeti-lo em diferentes momentos da escolarização, e a sequência, em assumir o conteúdo anterior como referência e aprofundá-lo gradativamente, permitindo aos alunos incorporarem elementos antes não captados e, com isso, se apropriarem de uma prática que se apresentará ainda mais complexa. Já a organização horizontal projeta o que ensinar em um ano específico e articula os conteúdos com as diferentes disciplinas, o que implica problematizá-los de acordo com as especificidades dos anos/séries, expressas na maturidade cognitiva, cultural, motora e afetiva dos alunos.

Com base naquilo que os professores afirmam ensinar ao longo da escolarização, sinalizamos a necessidade de melhor delineamento de objetivos que projetarão o que os alunos precisam aprender. Posteriormente, com o 
intuito de sistematizar esses objetivos de aprendizagem, faz-se relevante considerar as especificidades dos alunos, do contexto e da natureza do conteúdo, para que o professor defina o que e o quando ensinar.

\section{Considerações finais}

O estudo busca compreender como os professores do Município de Cachoeiro de Itapemirim/ES atuam nos processos de seleção e sistematização dos esportes, ao longo dos anos da escolarização.

Os resultados da pesquisa demonstram que a importância das atividades, assim como, uma ordem de conteúdo no processo de ensinar, estão associados a formação dos educadores, ou seja, há uma evidencia em psicomotricidade, logo, acreditamos ser necessário um delineamento de objetivos, que projetarão o que realmente os alunos precisam aprender.

A análise sobre o que os professores mais ensinam, acena para uma maior concentração no esporte, apesar de jogos e brincadeiras estar com maior diversificação. Isso pode estar associado ao fato de que os alunos buscam nas aulas de Educação Física um momento de "prazer e lazer". Essa centralidade do futebol nos leva, também, a refletir sobre a influência dos meios de comunicação para divulgar o ensino da modalidade, inclusive na escola.

Diante desse panorama, acenamos para estudos que evidenciem as matrizes curriculares dos municípios como base para elaboração de plano de ensino dos professores.

\section{Referências}

ARRUDA JÚNIOR, Norair Alves de. A competição e a Educação Física escolar. 2009. 57 f. TCC (Graduação) - Curso de Educação Física, Universidade Federal de Campinas, Campinas, 2009.

BRASIL. Secretaria de Educação Fundamental. Parâmetros curriculares nacionais. Brasília: MEC/SEF, 1997.

BRASIL. Ministério da Educação e do Desporto: Secretaria de Educação Fundamental. Parâmetros curriculares nacionais: Educação Física, $3^{\circ}$ e $4^{\circ}$ ciclos. Brasília, 1998, v. 7. 
BRASIL. Ministério da Educação. Lei de Diretrizes e Bases da Educação Nacional. Brasília, 1996.

BORBA, A. M.A infância na escola e na vida: uma relação fundamental. In: BEAUCHAMP, J; PAGEL, S D; NASCIMENTO, A $R$ Ensino fundamental de nove anos Brasília: MEC, 2007. P. 33-46.

CAILLOIS, R. Os jogos e os homens: a máscara e a vertigem. Lisboa: Cotovia, 1990.

CACHOEIRO DE ITAPEMIRIM. Dados preliminares do cadastro de demanda atendida por modalidade das unidades de ensino da rede municipal de Cachoeiro de Itapemirim-ES/2018.

CHARLOT, B. Da relação com o saber: elementos para uma teoria. Porto Alegre: Artmed, 2000.

Ensinar a educação física ou ajudar o aluno a aprender o seu corpo-sujeito?. In: DANTAS JÚNIOR, H. S.; KUHN, R.; RIBEIRO, S. D. D. Educação física, esporte e sociedade: temas emergentes. São Cristóvão: Editora da UFS, 2009. v. 3, p. 231-246.

COSTA, L. C. A. da; NASCIMENTO, J. V. do. Prática pedagógica de professores de educação física: conteúdos e abordagens pedagógicas. Revista da Educação Física/UEM, Maringá, v. 17, n. 2, p. 161-167, 2. sem. 2006.

DARIDO, Suraya Cristina. Os conteúdos da Educação Física escolar: influências, tendências, dificuldades e possibilidades. Revista Fluminense de Educação Física Escolar, Niterói, v. 2, n. 1, p. 5-25, 2001.

DARIDO, Suraya Cristina; Educação Física na escola: questões e reflexões Araras: Topázio. 2003.

DARIDO, Suraya Cristina.A educação física na escola e o processo de formação dos não praticantes de atividade física. Revista Brasileira de Ciências do Esporte Campinas: V 18, n¹ p 61-80; Jan/Mar , 2004.

DARIDO, Suraya Cristina. Os conteúdos da Educação Física escolar: influências, tendências, dificuldades e possibilidades. Revista Fluminense de Educação Física Escolar, Niterói, v. 2, n. 1, p. 5-25, 2001.

DARIDO, S. C.A Educação Física na escola e o processo de formação dos não praticantes de atividade Física. Revista Brasileira de Ciências do Esporte Campinas: V 18, n¹ p 61-80; Jan/Mar , 2004.

DARIDO, S. C.; SOUZA JÚNIOR, O. M.Para ensinar educação física: possibilidades de intervenção na escola. Campinas, 2007.

DARIDO, S. C.; SOUZA JÚNIOR, O. M.Refletindo sobre a tematização do futebol na Educação Física escolar. Rio Claro, 2010. 
KRAVCHYCHYN, C.; OLIVEIRA, A. A. B. de; CARDOSO, S. M. V. Implantação de uma proposta de sistematização e desenvolvimento da educação física do ensino médio. Movimento, Porto Alegre, v. 14, n. 2, p. 3962, maio/ago. 2008.

MATOS, Juliana Martins Cassani. Conteúdos de ensino da Educação Física escolar: da produção acadêmica as narrativas docentes. Vitória, 2013.

MARZINEK, A.A motivação de adolescentes nas aulas de educação física. Dissertação (Pós-graduação) - Programa de pós-graduação Stricto Sensu em Educação Física, Universidade Católica de Brasília, Brasília - DF, 2004.

MATOS, Juliana Martins Cassani; VIEIRA, Aline de Oliveira; NETO, Amarílio Ferreira. A seleção e a sistematização dos conteúdos de ensino: a perspectiva de professores do Espírito Santo.

OLIVEIRA, D. A.; VIEIRA, L. M. F. et al. Trabalho docente na educação básica no Brasil. - Belo Horizonte: Universidade Federal de Minas Gerais, Grupo de Estudos Sobre Política Educacional e Trabalho Docente, 2013.

PEREIRA, F. M.; SILVA, A. C. da. Sobre os conteúdos de ensino da educação física no ensino médio em diferentes redes educacionais do Rio Grande do Sul. Revista da Educação Física/UEM, Maringá, v. 15, n. 2, p. 6777, 2. sem. 2004.

ROSÁRIO, Luís Fernando Rocha; DARIDO, Suraya Cristina. A sistematização dos conteúdos da educação física na escola: a perspectiva dos professores experientes. In: Revista Motriz, Rio Claro, v. 11, n. 3, p. 167-178, set/dez, 2005.

SANTOS, Silvan Menezes dos; MEZZAROBA, Cristiano; A busca pelo ensino do esporte da escola em meio às manifestações do fenômeno esportivo na sociedade contemporânea. In: Revista Conhecimento Online, out, 2013, vol. 2.

SANTOS, W. dos. A relação dos alunos com os saberes nas aulas de educação física.J. Phys. Educ., Maringá, v. 27, e2737, 2016.

SILVA, J. V. P.; DAGOSTIN, K. U. D.; NUNEZ, P. R. M. Educação física e conteúdos trabalhados nas séries iniciais do ensino fundamental. Motriz, Rio Claro, v. 1, n. 3, p. 592599, jul./set. 2009.

\section{Notas}

Aprovação de comitê de ética em pesquisa.

Pesquisa aprovada pelo Comitê de Ética da UFES sob o $\mathrm{n}^{\circ}$ 15419913.4.0000.5542. 


\section{Sobre os Autores}

\section{Mauricio Lopes Spinola}

mauricio-spinola@hotmail.com

Professor da Prefeitura Municipal de Cachoeiro de Itapemirim/ES. Mestre em Educação pela FVC - Faculdade Vale do Cricaré. Pós graduado em Educação Física Escolar e Psicomotricidade pela FACl - Faculdade de Tecnologia Cachoeiro de Itapemirim (2016). Graduação em Licenciatura em Educação Física pelo Centro Universitário Claretiano (2015).

\section{Juliana Martins Cassani}

julianacassani@gmail.com

Professora do Programa de Pós-Graduação em Ciências, Tecnologia e Educação da Faculdade Vale do Cricaré (Mestrado Profissional). Faz estágio Pós-Doutoral em Educação Física pela Universidade Federal do Espírito Santo - Ufes. Doutora em Educação Física pela - Ufes. Mestre em Educação Física pela Ufes. Graduação em Educação Física (Licenciatura e Bacharelado) pela Universidade Vila Velha (2011) e em Ciências Contábeis pela Ufes (2002). Membro do Instituto de Pesquisa em Educação e Educação Física - Proteoria, em que atua nas linhas de pesquisa Formação Profissional, Currículo e Práticas Pedagógicas em Educação e em Educação Física e História da Educação, da Educação Física e do Esporte. Tem experiência na área de Educação e Educação Física, com ênfase em Currículo, Avaliação Educacional e História, atuando principalmente nos seguintes temas: práticas pedagógicas, avaliação, livros didáticos, imprensa periódica, manuais e compêndios escolares 